\title{
KNOWLEDGE, ATTITUDE AND PRACTICES REGARDING “THE ROLE OF SPIRITUALITY IN CURRENT MEDICAL PRACTICE AMONGST MEDICAL PROFESSIONALS" IN A TERTIARY CARE HOSPITAL.
}

\author{
M.M. Jain, Abhijeet Joshi, Nikhil G. Tayade, S.R. Jaiswar, Karan B. Thakkar
}

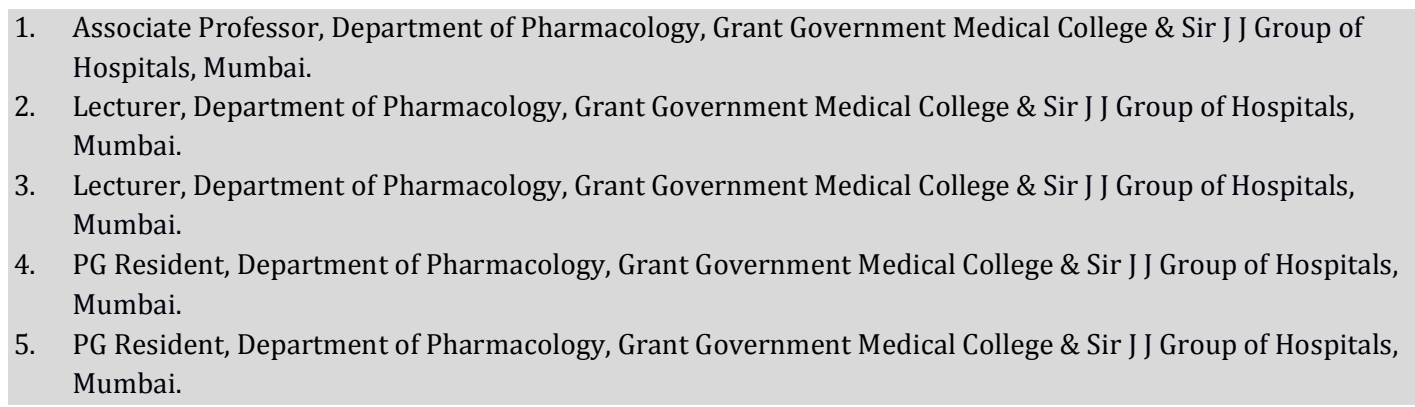

\section{CORRESPONDING AUTHOR}

Dr. M.M. Jain,

Associate Professor, Dept of Pharmacology,

Grant Government Medical College \&

Sir J J Group of Hospitals, Mumbai

E-mail: mangalmjain@gmail.com

Ph: 00919920066441

\begin{abstract}
INTRODUCTION: Spirituality has been integral part of medicine and health since ancient age. This has been accepted in various developed countries as evident by a plethora of published articles. However, the extent of spiritual component in medical practice in India is largely unknown. The present study is a questionnaire based study to assess the extent of knowledge (awareness), attitude and practices among medical professionals at a tertiary care Hospital regarding role of spirituality in management of health and diseases. METHODS: A predesigned validated list of questionnaire was distributed among 250 doctors of all specialties at the hospital along with brief introduction on purpose and scope of the study. The questions were collected back personally after giving sufficient time to attempt them. Doctors were evaluated regarding their knowledge, attitude and practice about spirituality in medicine using multiple choice question format. RESULTS: The response rate from participants was $80 \%$ $(200 / 250)$. More than $90 \%$ participants had a good deal of knowledge of spirituality but unable to distinguish between truly spiritual practices from traditionally followed religious rituals. More than $70 \%$ felt that there is relevance of spiritual practices in health and diseases but pointed out lack of credible scientific data to incorporate these in health management strategy. There was wide variation among participants regarding underlying mechanism/s responsible for spiritual healing. Most of them believed this to be Psychological (90\%), Neuroendocrine $(70 \%)$ or Immunology (26\%) and only (4\%) attributed it to all these factors. Majority of the participants agreed that spirituality offers maximum health benefits in chronic and incurable diseases.

Participants vouched for introduction of spiritual medicine in medical curriculum to be taught by medical professionals with expertise in spirituality. They also opined that there is need to involve health care professionals in spirituality related research work.
\end{abstract}


CONCLUSION: The KAP study shows a huge gap between physician's perception and reality about spirituality. A comprehensive report on concept and application of spirituality in health is lacking. There is an urgent need to undertake concerted and collaborative work by dedicated and qualified professionals to establish role of spirituality in health and diseases.

KEY WORDS: Spirituality; Holistic health; Health Knowledge, Attitude, Practice; Mind body relations, Metaphysical; Complimentary therapies

INTRODUCTION: "The distance you have gone is less important than the direction in which you are going. - Leo Tolstoy

According to WHO definition of health, it is not just freedom from disease but a positive state in terms of physical, social, psychological, mental and spiritual well being. Going by a comprehensive WHO report in recent past, it is clearly evident that the present treatment strategy is neither successful nor effective in controlling the diseases, particularly Non Communicable diseases (NCD). ${ }^{[1,2]}$ A number of chronic and incurable diseases like diabetes ${ }^{[3]}$; hypertension ${ }^{[4]}$, IHD[5], depression and malignancies ${ }^{[6]}$ have assumed epidemic proportion and their effective control with available means seems impossible. Equally important is the increase incidence of unsocial and potentially dangerous activities like rape, murder, violence, suicides and mindless shooting on slight provocation. Despite remarkable advances in science and technology and in-depth understanding of molecular biology, the mute question that remains to be answered is "where lies the fault?"

Several hundred years ago, Hippocrates, the father of modern medicine, warned the health care professionals, saying "the greatest error committed by the physicians is that they do not take soul in to account for therapy." James S.Gordon, the founder- director of Mind-Body-Medicine at Georgetown University, Washington, DC wrote that medical education today is "long on technical mastery but short on issues of personal and spiritual growth". In fact, a great deal of published data indicated undisputed health benefits from spiritual interventions $[7,8,9]$. Unfortunately, this is lacking in modern medical practice. The fault may thus be attributed to lack of spiritual dimension in health management.

The concept of spirituality may differ from person to person based on one's social, ethical, religious or cultural background. Nevertheless, some fundamental principles remain common to all spiritual philosophy irrespective of its origin. Whether it is preksha dhyaan of Jains or Kriyayoga of patanjali, Rajyoga of Bramhakumari or transcendental relaxation technique of modern medicine, and another 200 different spiritual formats, albeit different in procedure, but all have the common goal of restoring brain and bodily imbalances caused by a host of endogenous and exogenous factors. [10,11] Dr. Dean Ornish, a staunch proponent of spirituality for health benefits, has documented reversal of coronary artery occlusion by diet and meditation.[12,13] Other investigator also reported similar finding in their studies.[14,15] In yet other studies, the EEG pattern of volunteers subjected to meditation showed favorable changes equivocally in all the volunteers at the behest of meditation.[16,17] More recently, an opinion poll among American population indicated that a great majority of them believed in spirituality and that their recovery from illness or injury was influenced by spiritual discussions, suggestions and interventions. ${ }^{[18]}$ Interestingly, America became the first country to introduce teaching and training of spiritual practices in medical curriculum.[19,20] UK and other developed countries followed the suit.

With respect to India, practice of yogic healing dates back around 2500 years. Lord Mahavira advocated principle of absolute ahimsa for sound health not only in terms of physical non-violence but also with respect to purity of thoughts, deeds or action. Only recently, 
scientific evidence support age-old belief that thought process is greatly linked with immune system. [21, 22] Charak Samhita and Shushrut Samhita during that time described a system of health which focused on health promotion by using herbs and through meditation. The health system promised conquest of ageing and cure from disease by regular practice of sutras. Over the years, such practices were forgotten in the quest of scientific proof. As a matter of fact, science can explain how the human body works. It may provide necessary tools to examine physiological and pathological processes in health and disease but it cannot invigorate body's mechanisms for the advanced health gains. In 1978, India's representative to WHO inspired by the vision of last Yog Siddha, Sir Arabindo proposed that the definition of health should be enlarged to cover Spiritual well being in addition to its physical , mental and social counterpart. The proposal was considered at $36^{\text {th }}$ world assembly in 1983 . Subsequently, $37^{\text {th }}$ world health assembly in 1984 adopted the historical resolution that the spiritual dimension should be added to the scope of health. The summary proceedings were released at the national workshop held at Bangalore in February 1985. [23] Barring few contemporary practitioners in India, who continued to adopt rich heritage of ancient times, the modern medical practitioners essentially remained aloof from these valuable therapeutic interventions till such time we received very strong signals from the west. We being at the helm of affair in health management and having convinced health benefits of spirituality should take the call to reinvent ancient methods of health management validated through the scientific temper of modern era.

Before beginning the process of introducing new concepts in medical curriculum, it is first necessary to assess perception of medical professionals regarding the concept and the need to introduce it. Conducting KAP study can do this best. Therefore, the present study was undertaken to assess the extent of knowledge (awareness), attitude and practice among medical professionals regarding the role of spirituality in management of health.

AIMS AND OBJECTIVE: The aim of the study was to assess the extent of Knowledge, Attitude and Practice among medical professionals regarding the role of spirituality in management of health.

MATERIAL AND METHODS: Study was conducted in the month of April - May, 2011 at Grant Medical College and Sir J J Group of Hospitals, Mumbai. Institutional Ethics committee permission was taken prior to start of the study.

Study participants included teaching faculty in pre-clinical, Para-clinical and clinical departments including resident doctors pursuing post-graduate courses in various subjects at the institute. A set of questionnaire was prepared according to standard format for KAP studies. [24] Initially questions were pilot tested on 20 participants selected randomly for adequacy and validation purpose. Suitable modifications were made according to response from the pilot study. Subsequently, the final set of questionnaire was distributed among 250 participants and collected back personally. The participants had liberty to attempt some or all questions and also they were free to mark more than one option if so desired.

Questionnaire (Appendix-I) - The questions were designed to seek information under following heads:

Demographic data: This includes age, gender, Area of specialization, year of experience and religion.

Knowledge - There were 13 questions in this section constructed to know the extent and depth of understanding about spirituality among participants. 
Attitude - There were 11 questions in this section corroborated with questions in knowledge section.

Practice - There were 8 questions in this section to evaluate participant's practical application of knowledge and attitude.

STATISTICAL ANALYSIS: Results were expressed in percentage response.

RESULTS: Out of a total of 250 participants, 200 responded to our appeal making the response rate of $80 \%$. The reason/s from non responders was/were not secured. Thus the following result represents response from 200 participants who had attempted questions in full or in part.

KNOWLEDGE: In response to awareness about spirituality in health, almost all the participants opined in favor of having some knowledge of health benefits from spiritual practices. In addition, $5 \%$ of the participants claimed to have advanced insight in spiritual medicine. As many as $73 \%$ opined that there is relevance of ancient spiritual practices to modern health management but $27 \%$ of the participants denied any such co-relation. $82 \%$ of the participants also agreed that religious philosophy of ancient time is complimentary to medical treatment for the patients.

Almost $88 \%$ of the participants considered that spirituality has sound scientific basis in the context of current scientific knowledge but $12 \%$ denied any such connection. Notably, all the participants agreed that spirituality is different from superstitions or blind faith.

Regarding mechanisms responsible for spiritual healing, 90\% attributed it to Psychological, $70 \%$ to Neuroendocrine, $26 \%$ to immunological and only $4 \%$ said that all the above mentioned factors are responsible. (Figure -1)

Regarding a question on ill effects of spirituality, $86 \%$ responded in negative and $12 \%$ did not respond at all. Only $2 \%$ had consented that spiritual practices may have ill effects on health of its follower.

Regarding, a question on beneficial effects of Spirituality, $97 \%$ responded in affirmation. In response to a question on reliability of available literature on spirituality, $59 \%$ were of the opinion that published data is trustworthy whereas $18 \%$ expressed doubts on its reliability. $23 \%$ did not respond to this question.

With regard to increase in the incidence of diseases, $91 \%$ of the participants opined in favor while $9 \%$ opined against it.

On further exploration for reason/s, $77 \%$ attributed this to improved diagnostic modalities, around $45 \%$ stood for robotic treatment approach, modern life style and environmental degradation while $24 \%$ cited overzealous competition as the possible causes for increase in incidence of diseases. (Fig No. 2)

Regarding a question on which system of medical science has greater emphasis on spirituality, around 50\% participants mentioned Ayurveda or Homeopathy but none mentioned about allopathy.

To a question whether spiritual practice is a compromise to limitations of medical therapy, $81 \%$ disagreed while $7 \%$ agreed to this. Rest of the participants did not comment.

ATTITUDE: In response to the question on what constitute spiritual practices, around $70 \%$ considered pilgrimage tour, charity, helping the poor and downtrodden, regular prayer and/or 
meditation are forms of spiritual practices \& 40\% opined in favor of Transcendental Relaxation Techniques, protection of animals and environment while $20 \%$ cited Ahimsa, recital of Mantras, observance of silence or keeping pets as spiritual practices. Only $3.5 \%$ attributed all the activities under this question as forms of spiritual practices. (Figure $-3 a \& 3 b$, Table -2 )

In response to the question on spiritual medicine as a separate department in the hospital, $42 \%$ opined in favor while $6 \%$ opined against it. $52 \%$ responders remained undecided. When asked regarding improved longevity but reduced quality of life with present health management, $31 \%$ agreed while $33 \%$ disagreed. $36 \%$ participants remained noncommittal on this issue.

When asked if spirituality deprive the patients from rational therapy, $45 \%$ of participants denied this but $11 \%$ agreed to this. $44 \%$ participants remained non committal.

With regard to a question on faculty for spiritual teaching, $20 \%$ wished that it should be taught by spiritual gurus while $34 \%$ did not feel so. $56 \%$ of the participants did not respond.

To another question on faculty requirements, $68 \%$ opined that preferably a medical person with spiritual background should teach spirituality.

In response to the question on inclusion of spirituality in medical curriculum, 34\% opined in favor of it while $6 \%$ opined against it. As many as $60 \%$ participants remained undecided. Regarding a separate postgraduate course in spiritual medicine, $24 \%$ favored it while $17 \%$ opposed it. Again, $59 \%$ of the participants remained undecided.

In response to a question regarding research work on spirituality, $75 \%$ felt that only doctors should engage for such activities while $25 \%$ had broader view and opined that many people like spiritual preachers, social activists and philanthropists may participate in spirituality related research. In response to a question on possible areas where spirituality may be helpful, $78 \%$ cited chronic, incurable diseases and terminal illness cases as possible targets where spiritual intervention may help.

PRACTICE: With regard to a question on relevance of religious rituals to health issues, $70 \%$ felt that these are related but $23 \%$ did not feel so. $7 \%$ remained undecided.

Regarding participant's inclination towards spirituality, $92 \%$ opined that they read articles on spirituality occasionally while $8 \%$ never read any such articles. However, with regard to participation in spirituality related academic events, only $24 \%$ participants attended that too occasionally. Only $16 \%$ participants opined that patients do inquire about alternative therapy for their ailments. However, the participants never deliberated in detail on spirituality nor the patients were referred to any centre to reinforce health implications of spiritual practices. Interestingly, 98\% participants followed spirituality health practices for their own health. Only $2 \%$ participants denied any kind of spiritual engagement in their life. (Figure - 4)

DISCUSSION: Spiritual aspect of health management is not a new concept. It existed long before evidence based medicine has taken a lead in management of health and diseases. However, over jealous competition, materialistic pleasure and increased cost of medical education have bereft the professional's mind of spiritual imprint in present time. The resultant effects are here for all of us to witness. Very recently, a study involving 15,662 adult subjects randomly selected across eight Indian states have shown that nearly $35 \%$ and $41 \%$ of the study population was suffering from Diabetes and Hypertension respectively. Other surveys by health management staff in last 2 years also indicated increased prevalence of Asthma, Alzheimer, Arthritis, Cancers and Depression. Interestingly, a plethora of published report indicated overwhelming response to 
spiritual interventions in management of all these diseases.[25] More importantly, some of the indexed text books of medicine and physiology have introduced separate chapters on Spiritual medicine in their latest editions.[26,27] With respect to India, the medical professional's perception about spirituality is largely unknown except initiative by India way back in 1978.

The present study was an attempt to explore level of understanding about spirituality among medical professionals at a tertiary care hospital.

From the results of this study, it appears that majority of the participants had a good deal of knowledge regarding spirituality and its positive impact on health. They have shown keen interest in the subject topic and attended all the questions diligently. As many as 50 participants also commented on this relatively unexplored area of medical science and made many positive suggestions to advance the topic further. [Appendix 2] Even though, spirituality is not the part of medical curriculum at present, easy access to information highways and advances in communication technology have made it possible for the participants to keep updated with latest developments in any field of medicine. Spiritual medicine is no exception.

From the survey, it is evident that majority of the medical professionals were aware of spiritual aspects of health care but lacked precise understanding of what really constitute spiritual practices and the scientific basis of spiritual healing. As a matter of fact, all the activities under the related question were part of spiritual practices but varied in terms of their significance. For instance, activities such as charity, donations, prayers, pilgrimage and reciting mantras, which are more of rituals rather than spiritual and do not merit health benefits, have been termed as spiritual by majority of the participants. On the other hand, activities like ahimsa, meditation, protection of animals and environment, regular fasting and transcendental relaxation techniques, which are truly spiritual as evident from published reports, were chosen only by few. [28] This is nonetheless expected as the meaning of spirituality is highly debatable subject and there are no clear guidelines as to what constitute spiritual practices. Whatever spiritual insight a medical practitioner acquires is through chance encounters with spiritual gurus, religious preachers, parents, colleagues and friends or from news papers and magazines. This results into lack of consistency and uniformity among medical professionals in adopting, interpreting, analyzing and translating concept of spirituality in health and diseases. There is an urgent need to define spiritual practices and adopt a pragmatic approach in implementing them. Another major flaw in the knowledge of participants was about underlying mechanism/s responsible for health benefits from spirituality. Almost, $90 \%$ participants attributed psychological as a major factor. However, the current literature convincingly indicated that functional alterations in neuroendocrine and immunological processes are responsible for alleviating human sufferings and restoring good health in a number of chronic and incurable diseases as a result of spiritual interventions. $[29,30,31]$

Majority of participants felt that available data on spirituality is inadequate and lacks credibility. The reason for this may be two fold. Firstly, as appears from demographic data (Table -1) that almost 75\% participants were young medical professionals who may not have enough exposure to scientific data on spirituality because of their proximity to modern medicine and alternative approach of health care is usually sidelined. Secondly, not many qualified and experienced medical professionals are willing to take up research in the field of spiritual medicine. Consequently, there is lack of scientific data on spirituality from India's perspective. It is desired that qualified and experienced medical professionals at academic institutions shall take up concerted research on spirituality to dispel truth about its health benefits or otherwise. 
Majority of the participants favored a basic course on spirituality at undergraduate level but denied advance courses either for UG or PG. This is expected as the existing curriculum for UG/ PG courses do not leave any scope for further increase in subject load on the students but preliminary exposure to spirituality at UG level warrant current situation in keeping pace with present developments.

As far as spiritual dimension of medical practice is concern, it is not the trend with modern medical practitioners. However, they keep an open mind to patient's queries regarding spirituality but leave the choice at the discretion of patients without dwindling on either side. Surprisingly, 98\% participants do practice spirituality for their own good. This paradox can be explained from the fact that a medical practitioner is too busy to adopt spiritual dimension in treatment strategy for his patients so even if a practitioner is fully convinced about health benefits of spiritual intervention, he tends to avoid it in day to day practice. Moreover, lack of scientific support for any such intervention may trigger a legal issue if the patient misread the very purpose and scope of the spiritual intervention. The present medical curriculum is also responsible for lack of spiritual dimension in modern medical practice. It puts undue emphasis on drug treatment for physical comfort and symptomatic relief rather than total health status as defined by WHO.

CONCLUSIONS: The KAP study on spirituality shows a huge gap between physician's perception and practice. A comprehensive report on concept and application of spirituality in health management is lacking. It reveals that what matter most to medical practitioners is not the religious preaching of pre-designated rituals but well documented scientifically proved spiritual concepts to manage health and disease individually and collectively. Induction of medical scientist in spirituality related research shall boost confidence of medical practitioners in spirituality and generate reliable data. Based on this study, we believe that there is an urgent need to undertake concerted and collaborative work by dedicated and qualified professionals to redefine place of spirituality in health and disease as was norm during ancient time.

\section{ACKNOWLEDGMENT:}

- We are grateful to Dr. T.P. Lahane Dean, Grant Medical College \& Sir JJ Group of Hospitals and Dr. S. B. Patel, Professor of Pharmacology, Grant Medical College \& Sir JJ Group of Hospitals for their permission to conduct the study at this centre.

- We are also grateful to Dr. D.V. Kaundinya, Ex - Professor of Microbiology, and Dr. (Mrs). S.D. Kaundinya, Professor of Physiology, Grant Medical College \& Sir JJ Group of Hospitals for their valuable suggestions from time to time during evolution of questionnaire.

- We are sincerely thankful to all our participants for their active participation in the study and valuable comments.

\section{REFERENCES:}

1. Alwan A, MacLean D, Mandil A. Assessment of National Capacity for Noncommunicable Disease Prevention and Control. Geneva, Switzerland: World Health Organization; 2001. 
2. Ala Alwan, David R MacLean, Leanne M Riley et al. Monitoring and surveillance of chronic non-communicable Diseases: progress and capacity in high-burden countries. Lancet 2010; 376(9755):1861 -1868.

3. Chan JC, Malik V, Jia W, et al. Diabetes in Asia: Epidemiology, risk factors, and pathophysiology. JAMA 2009; 301:2129-40.

4. Patricia M Kearney, Megan Whelton, Kristi Reynolds, Paul Muntner, Paul K Whelton, Jiang He. Global burden of hypertension: analysis of worldwide data. Lancet 2005; 365: 217-23.

5. Stephanie Ounpuu, Sonia Anand, Salim Yusuf,. The Global Burden of Cardiovascular Disease <http://www.medscape.com/viewarticle/420877 accessed on 22/11/2011>].

6. Global cancer rates could increase by $50 \%$ to 15 million by 2020 http://www.who.int/mediacentre/news/releases/2003/pr27/en/ accessed on 22/11/2011.

7. Seybold, K. S., and P. C. Hill.The Role of Religion and Spirituality in Mental and Physical Health: Current Directions in Psychological Science Chan JC, Malik V, Jia W, et al. Diabetes in Asia: Epidemiology, risk factors, and pathophysiology. JAMA 2009;301:2129-40.

8. Madanmohan, Mahadevan SK, Balakrishnan S, Gopalakrishnan M, Prakash ES. Effect of six weeks yoga training on weight loss following step test, respiratory pressures, handgrip strength and handgrip endurance in young healthy subjects. Indian J Physiol Pharmacol 2008; 52: 164-170.

9. Manchanda SC, Narang R, Reddy KS, Sachdeva U, Prabhakaran D, Dharmanand S, Rajani M, Bijlani R. Retardation of coronary atherosclerosis with yoga lifestyle intervention. J Assoc Physicians India 2000; 48: 687-689.

10. Shapiro, S.L., Carlson, L., Astin J., Freedman, B. Mechanisms of mindfulness. Journal of Clinical Psychology 2006, 62(3), 373-386.

11. Shapiro, S.L., Astin J., Bishop S., Cordova M. Mindfulness-based stress reduction and health care professionals. International Journal of Stress Management 2005, 12(2), 164-176.

12. Ornish DM, Scherwitz LW, Doody RS et al. Effects of stress management training and dietary changes in treating ischeamic heart disease. JAMA 1983; 249: 54 -59.

13. Ornish DM, Scherwitz LW, Brown SE et al. Adherence to life style changes and reversal of coronary atherosclerosis. Circulation 1989; 4: 11- 57.

14. Patel C, Marmot MG, Terry DJ, Carruthers M, Hunt B and Patel M. Trial of relaxation in reducing coronary risk: four year follow up. British Medical Journal 1985; 290: 1103 - 06.

15. Roth D, Kostuk WJ. Non invasive and invasive demonstration of spontaneous regression of coronary artery disease. Circulation 1980; 62: 888 - 96.

16. Luders E, Toga AW, Lepore N, Gaser C. The underlying anatomical correlates of long-term meditation: larger hippocampal and frontal volumes of gray matter. Neuroimage. 2009; 45:672-8.

17. Payne IR, Bergin AE, Loftus PE. A review of attempts to integrate spiritual and standard psychotherapy techniques. J Psychother Integration 1992; 2:171-192. 
18. Klaker FD, Gorsuch RL, Tan SY. Therapist use of religious and spiritual intervention in Christian counselling. A preliminary report. Counselling and values, 2005; 49 (2) 107 -119.

19. Christina M Puchalski, David B Larson, Francis G Lu. Spirituality in Psychiatry residency training programs. International review of Psychiatry 2001; 13(2): 131- 138.

20. Puchalski,C.M and Larson D.B. . Developing curricula in spirituality and medicine. Academic medicine: Journal of the association of American medical colleges 1998; 73(9):970 - 974.

21. Gail Ironson, Mario Odriguez, Debra Greenwood and et al. Posttraumatic Stress Symptoms, Intrusive Thoughts, Loss, and Immune Function After Hurricane Andrew. Psychosomatic Medicine 1997; 59:128-141.

22. John FS, Cathleen Dobbs, David Brown, Bruce Zwilling. Psychoneuroimmunology: Stress effects on pathogenesis and immunity during infection. Clinical microbiology review 1994;5: 200-212

23. Rup Nagpal, Manoj das, Kerr white health collection. The spiritual dimension of health: including summary proceeding of the national workshop held at Bangalore in February 1985.publisher: Directorate general of health services, Government of India, 1985.

24. K. Kaliyaperumal. Guideline for Conducting a Knowledge, Attitude and Practice (KAP) Study. AECS Illumination 2004;4(1): 7 - 9.

25. Paul S. Mueller, David J. Plevak, Teresa A. Rummnas. Religious Involvement, Spirituality, and Medicine: Implications for Clinical Practice. Mayo Clin Proc. 2001; 76:1225- 35.

26. C. Eklund. Complementary and alternative medicine. In, Kasper, Brawnwald et al. Harrison's principle of Internal medicine, 17th edition, Newyork, Mc Graw Hill companies, 2010;56 -60.

27. R.L. Bijlani, S. Manjunatha.Yogic practices: Meditation. In RL Bijlani (ed).understanding medical physiology: a Textbook for medical students, $4^{\text {th }}$ edition. New delhi , Jaypee Brothers, 2011;760 -764.

28. Jean L. Chan, Giuseppe Matarse, Greeshma K, shetty,et al. Differential regulation of metabolic, Neuroendocrine and immune function by leptin in human.2006 by proceeding of national academy of science of the USA.

29. Seybold, K. S., P. C. Hill. The Role of Religion and Spirituality in Mental and Physical Health.Current Directions in Psychological Science 2001;10(1):21 - 24.

30. Mclllmurray MB, Francis B, Harman JC, Morris SM, Soothill K, Thomas C. Psychosocial needs in cancer patients related to religious belief. Palliative Medicine 2004; 17: 49-54.

31. Yates JW, Chalmer BJ, St. James P, et al. Religion in patients with advanced cancer. Med Pediatr Oncol 1981; 9:121 - 8. 


\section{Appendix - 1: Questionnaire}

\section{Knowledge, Attitude and Practices regarding "the role of Spirituality in Current Medical Practice amongst Medical Professionals" in a tertiary care Hospital}

\section{General Information:}

(We wish that the respondent should reveal his/her identity but if you do not wish you may enter your initials only)

Name:

Age:

Sex:

Religion:

Qualification:

Experience (post MBBS): $\quad$ Years

Knowledge: (tick one or more responses whenever applicable)

- According to you, awareness about spirituality in health management among medical Professionals is (\%)
[ ] $0-25$
[ ] $26-50$
[ ] $51-75$
[ ] $76-100$

-Are ancient practices of health care relevant to modern medicine?
[ ] Yes
[ ] No
[ ] can't say

-In general, Religious Philosophy \& Medical Science are

[ ] Complimentary [ ] Contradicting [ ] can't say

-Does Spiritual medicine have some scientific basis according to current knowledge of Science?
[ ] Yes
[ ] No
[ ] can't say

-Is there any difference between Spirituality \& Superstition/ blind faith?
[ ] Yes
[ ] No
[ ] don't know

-Which of the following mechanisms contribute to health promotion by spirituality?

[ ] Physical

[ ] Psychological

[ ] Neuro - endocrine

[ ] Immunological

-Does spirituality cause guilt, anxiety or other negative emotions that lead to increased patient suffering?
[ ] Yes
[ ] No
[ ] can't say 
-Does spirituality contribute to beneficial effects of Medical treatment?
[ ] Yes
[ ] No
[ ] can't say

-Do you think that the literature regarding spirituality in current scenario is comprehensive \& trustworthy?
[ ] Yes
[ ] No
[ ] can't say

-Do you agree that currently there is an increase incidence of chronic and incurable diseases?
[ ] Yes
[ ] No
[ ] can't say

-If answer to above question is yes then is it because of

[ ] Improved diagnostic methods

[ ] Robotic treatment approach

[ ] Modern life style

[ ] Overzealous competition

[ ] Environmental degradation

-Which branch of medical science has greater emphasis on spiritual practices?

[ ] Allopathy

[ ] Ayurvedic

[ ] Siddha

[ ] Homeopathy

[ ] Unani

[ ] None

- Indulgence in spiritual practice is it a compromise for inadequate medical knowledge?
[ ] Yes
[ ] No
[ ] can't say

Attitudes: (tick one or more responses whenever applicable)

-Which of the following can truly be called spiritual practices?

[ ] Ahimsa (Non violence)

[ ] Regular praying

[ ] Reciting Mantra

[ ] Observing silence for some time in a day

[ ] Regular Fasting

[ ] Protecting Animals (helping animals in distress)

[ ] Protecting environment

[ ] Donation to charities \& orphanages

[ ] Helping poor \& downtrodden

[ ] keeping pets 
[ ] Going to pilgrimage

[ ] Meditation (Dhyaan)

[ ] Transcendental relaxation techniques

-Every hospital should have a separate spiritual medicine department.

[ ] Strongly agree

[ ] Agree

[ ] Neutral

[ ] Disagree

[ ] Strongly disagree

-Medicine today has improved longevity but reduced Quality of life (QOL).

[ ] Strongly agree

[ ] Agree

[ ] Neutral

[ ] Disagree

[ ] Strongly disagree

-Spirituality misleads the patients from medically indicated therapy.

[ ] Strongly agree

[ ] Agree

[ ] Neutral

[ ] Disagree

[ ] Strongly disagree

- Doctors need spiritual Gurus to teach spirituality.

[ ] Strongly agree

[ ] Agree

[ ] Neutral

[ ] Disagree

[ ] Strongly disagree

-A Medical person with knowledge of spirituality will be better trainer in spiritual teaching.

[ ] Strongly agree

[ ] Agree

[ ] Neutral

[ ] Disagree

[ ] Strongly disagree

-Spirituality should form part of curriculum in training and teaching of medical students. 
[ ] Strongly agree

[ ] Agree

[ ] Neutral

[ ] Disagree

[ ] Strongly disagree

-There should be separate Postgraduate course on spiritual medicine?

[ ] Strongly agree

[ ] Agree

[ ] Neutral

[ ] Disagree

[ ] Strongly disagree

-In which of the following disorders, spirituality may have resounding effects?

[ ] Psychiatric illnesses in adults

[ ] Psychiatric disorders in children

[ ] Organic diseases

[ ] infectious diseases

[ ] Terminal illnesses

[ ] Social disorders

-Who should take up research work in spiritual practices to generate credible data?

[ ] Spiritual practitioner

[ ] Doctors

[ ] Social activist

[ ] Philanthropist

- A person in great despair is usually helped by spirituality.

[ ] Strongly agree

[ ] Agree

[ ] Neutral

[ ] Disagree

[ ] Strongly disagree

\section{Practices:}

-Do you relate Medical science to religious rituals in day to day practice?
[ ] Yes
[ ] No
[ ] can't say

-Do you read article on spirituality \& Health?
[ ] Yes
[ ] No
[ ] sometimes 
-Have you attended conference / workshop on "spirituality \& Medicines"/ Yoga for health/ mind body medicine?
[ ] Yes
[ ] No

-Have you encounter patients enquiring about role of spirituality in health and disease?
[ ] Yes
[ ] No
[ ] sometimes

-Are you referring any patients to spiritual lecture or meditation centre in modern day practice?
[ ] Yes
[ ] No
[ ] sometimes

-Do you motivate your patients for spirituality counseling as a part of treatment?
[ ] Yes
[ ] No
[ ] sometimes

•Does spirituality constitute part of your patient's management?
[ ] Yes
[ ] No
[ ] can't say

-Do you practice spirituality in any form for self health?

[ ] Yes [ ] No

-If yes, then which type of activities would you attribute as spiritual practices?

\section{Please write in brief your valuable suggestion / comment on this relatively unexplored topic.}




\section{Appendix - 2}

Comments from the participants for the study titled

\section{Knowledge, Attitude and Practices regarding "the role of Spirituality in Current Medical Practice amongst Medical Professionals" in a tertiary care Hospital}

-Please include the meaning of spirituality in practical life and its difference from superstitions.

- Systemic research by enlightened person should help.

- "Good topic", to be explored in current era.

-Great topic \& study. Looking forward for the results and analysis.

- Creating awareness specially in medical practitioners, convening medical professionals about the benefits of spirituality, research, putting spiritual practices (of yoga and meditation) as an adjuvant in treating patients.

-Good topic. Quite new and latest requirement of today.

-Good topic .it should be implemented in our hospitals as in US, UK.

-Spirituality has a role in medicine but it does not warrant the starting of a separate PG course in spiritual practice.

-To say I am spiritual person is totally wrong. Let others judge you. One must behave in such a way that others will appreciate your behaviour. This topic must be incorporated not only in medicine but in day to day life by all human being who will certainly reduce our suffering.

-Yoga is a best practice to be physically and mentally healthy.

-Good topic. Always denied by so many well famous practitioners. So keep the spirit high to spread awareness in community.

-It should be your own choice not compulsion.

-As far as surgery is concerned I feel that patients with incurable disease such as CA lung / stage IV CA breast, there patients are more receptive to spiritual healing.

-Extremely important nowadays because heavy workload and mental stress can lead the patients to the way of so many non communicable disease. To prevent such increased incidence of disease spirituality should come into picture.

- First of all, I would like to appreciate the way this topic has been raised. Stress is the only and most major culprit behind all the major illness. Everybody today is a victim of stress induced disorders and spiritual practices like meditating, reciting prayers, shlokas and social activities do a lot in reducing this stress and improving the health. 
-This will help to reduce the tension on medical students during their theory and practical exams.

$\bullet$ Keep the spirit high.

- I suggest for arranging an interactive session on this topic as a part of your ongoing study. I congratulate your project guide and you for selecting this important aspect in medical practice.

-I think we must do yoga or pranayam or transcendental medicine daily for atleast 15 or 30 min which can also be considered as part of spiritual practices.

-Very good topic. There is a increase in no. of patients as a severity of AIDS in populations. All of these people are totally demoralised in their life due to incurable nature of this disease so it will definitely help them to resolve their problems.

-Spiritual dimension in health is just an idea not a proven fact. It will only help up to certain extent, not beyond that if you advice 100 patients with fever it will not in all patients. But if you advice paracetamol tablet to those patients it will definitely work. Spirituality in medicine should be used as a preventive measure and not as a part of treatment. Don't give undue importance to spirituality in medicine. Patients will become more and more noncompliant to medicines by such things. Society itself wants a doctor who does not believe in spirituality. Its not like that in todays era spirituality has been reduced. Indian people have been practicing it since 100 years or more. So it should not be taken as a part of treatments on current era.

-It is good topic. On this aspect nothing great has been done so far. Hope your attempt should be great achieved milestone. Best of luck.

-Good topic with a innovative title to study upon. All the very best for it.

-An introduction to this topic should be included at this undergraduate level so that when doctors move on to the clinical practice, they have some ground knowledge in the subject. It is more of social science subject than medicines. Studies to a find a common ground are done by social science. Spirituality means different things in different people and social scientists can have an idea of this divergence.

-Spirituality should not be overdosed.

- "Spirituality" the word differs in meaning from person to person. Spirituality may be evaluated in incurable disease and terminal cancer and psychiatric patients.

- Medical practitioners like me are not fully aware I would like to gain more knowledge about its use and practice in health care.

-We would like to know more about the role of spirituality in health. Your step towards these aspects will definitely help in understanding the concept regarding spirituality. 
-This is very important and needful practice in modern medical practice. It can help to doctors as well as patient's life. I am also not well known about spirituality in depth. Very interesting topic. It should be included in modern treatment curriculum.

-It is required to change the attitude towards the spirituality.

- Meditation is must for the mental stability. It regulate the functions of various neuro endocrines organs which in returns help in regulating / maintaining function s of other body systems.

-Good topic. Data should be given with references.

- Lots of things have been written in spirituality books / even mythological stories, which draw some kind of scientific attention. I feel there should be a research / studies in details with medico professional and scientist going in credibility and digging out more things, getting more information on the relevance of facts in medicines and health practices.

-Spirituality is definitely great. But it is infact only a fractional part of this divine scheme of things in this universe. Many more truth apart from spirituality remains unravelled and unexplored. By all inclusive (i.e. scientist, scholars, spiritual gurus, spiritual leaders etc.) we know very few people are ware about spirituality. So your step towards this eternal truth can be major milestone.

-I strongly believe that spirituality has basis for good physical health.

-I do believe that spirituality to be a part of contributions of sense of well being. It does help in controlling rage, anger and anxiety. But also I believe that these emotions are essential as a reaction to whatever happens in the society. Spirituality should be propagated as a means of proper expressions and should help in development of good environmental for economic and social development. Also spirituality should be from personal and religious inclinations. Spirituality should be propagated as a complimentary or adjuvant to the medical treatment not as sole treatment for the disease of the person. For this spiritual guru should be unbiased and non judgemental so that they guide people in proper directions.

-I believe that these emotions are essential as a reaction to whatever happens in the society not as sole treatment for the disease of the person. For this spiritual guru should be unbiased and non judgemental so that they guide people in proper directions.

-It is very significant and ingratiating that relationship of spirituality with mind body and medicines is finally recognised, addressed and brought to the forefronts. Awareness among medical professionals regarding holistic approach in treating patients will help eliminations of disease at its roots.

-I personally feel that spirituality should be included as a part of modern therapeutics management especially for terminally ill patients and incurable disease.

-Spirituality should be propagated as a complimentary or adjuvant to the medical treatment. 
-Spirituality is not only keeping healthy mind also keeping healthy body. In this scenario many people are in search of proper spiritual activities. They need proper guidance, regularities and also learn advantages of it so they will be more motivated.

-Unless there is substantial proven evidence based understanding of the science behind the well accepted concept of benefits of spirituality in general well being mankind contemplating courses may be difficult with elements of misuse also. Hence though it is well acceptable that spirituality may have a bearing in the general well being of human being or there is a need to understand the science/basis behind it.

-I feel spirituality is a valuable adjuvant for keeping good health. Its use has been proved to be beneficial especially in cardiac disease and degenerative disorders. Doctor must be aware about beneficial effects of spirituality.

-This project should reach all the like minded medicine practitioners. It is need of hour particularly when treatment cost are skyrocking.

-I do believe that spirituality to be a part of contributions of sense of well being. It does help in controlling rage, anger and anxiety.

-Spirituality should be propagated as a means of proper expressions and should help in development of good environmental for economic and social development.

-Spirituality will definitely help in combating with psychiatric disease along terminal diseases where patient are quite deprived of emotional needs.

-Mechanisms discussed in the questionnaire were excellent with brief discussion in front which definitely help in understanding the truth.

-References should have been given.

-Examples in introduction part depict inclinations more towards yog - sadhana pattern which practically impossible in today's life style. Working on such topic may not give positive results but keep expectation at high level.

-Spirituality should be included in training and workshop and conferences but not at PG level.

-It should be more receptive and comprehensive while making other people to understand the facts regarding spirituality.

-Questions in knowledge sections were excellent. The numbering of the questions also has great impact on readers minds.

-It is medicines for purifying your soul.

- Comprehensive treatment programs for people living with AIDS recommend that the spiritual welfare of the patient, and its influence on their well-being, should be included.

-Environments that nurture self-awareness, including activities such as meditation and yoga, may promote fundamental changes in personal values that are spiritual in nature. 
These changes appear to be a significant aspect of healthy lifestyle change for many persons.

-The lifestyle change program focused on diet, exercise, self-awareness, selfunderstanding, and social support, and did not explicitly advocate a spiritual perspective.

-Previous study also confirmed that increased spirituality was positively associated with increased well-being, increased sense of meaning and purpose in life, and decreased tendency to become angry.

Table no. 1 - Demographic data of participants

\begin{tabular}{|c|c|c|c|}
\hline \multirow{2}{*}{ Title } & Subgroup & Number & Percentage (\%) \\
\hline \multirow{3}{*}{ Age (yrs) } & $21-30$ & 109 & $54.5 \%$ \\
\cline { 2 - 4 } & $31-40$ & 56 & $28 \%$ \\
\cline { 2 - 4 } & $41-50$ & 15 & $7.5 \%$ \\
\cline { 2 - 4 } & $51-60$ & 18 & $9 \%$ \\
\hline \multirow{5}{*}{ Sex } & 61 \&above & 02 & $1 \%$ \\
\cline { 2 - 4 } & Male & 131 & $65.5 \%$ \\
\hline \multirow{3}{*}{ Religion } & Female & 69 & $34.5 \%$ \\
\cline { 2 - 4 } & Hindu & 172 & $86 \%$ \\
\cline { 2 - 4 } & Muslim & 12 & $8 \%$ \\
\hline \multirow{5}{*}{ Experience (yrs) } & Others & 147 & $73.5 \%$ \\
\cline { 2 - 4 } & $<5$ & 22 & $11 \%$ \\
\cline { 2 - 4 } & $5-10$ & 10 & $5 \%$ \\
\cline { 2 - 4 } & $11-15$ & 9 & $6 \%$ \\
\cline { 2 - 4 } & $16-20$ & 12 & \\
\hline
\end{tabular}


Table no. 2 -Activities which were termed as Spiritual

\begin{tabular}{|c|c|c|c|}
\hline Sr.no. & Activities & $\begin{array}{l}\text { No. of respondent } \\
\qquad(n=200)\end{array}$ & $\begin{array}{c}\text { Percentage } \\
\text { (\%) }\end{array}$ \\
\hline 1 & Going to pilgrimage & 136 & 68 \\
\hline 2 & Donation & 111 & 55.5 \\
\hline 3 & Regular pray & 108 & 54 \\
\hline 4 & $\begin{array}{l}\text { Helping poor and } \\
\text { downtrodden }\end{array}$ & 102 & 51 \\
\hline 5 & Meditation & 94 & 47 \\
\hline 6 & Protect environment & 81 & 40.5 \\
\hline 7 & $\begin{array}{l}\text { Transcendental } \\
\text { Relaxation }\end{array}$ & 77 & 38.5 \\
\hline 8 & Protect Animals & 73 & 36.6 \\
\hline 9 & Observe silence & 43 & 21.5 \\
\hline 10 & Keeping Pets & 42 & 21 \\
\hline 11 & Ahimsa & 39 & 19.5 \\
\hline 12 & Reciting Mantras & 26 & 13 \\
\hline 13 & All & 7 & 3.5 \\
\hline
\end{tabular}

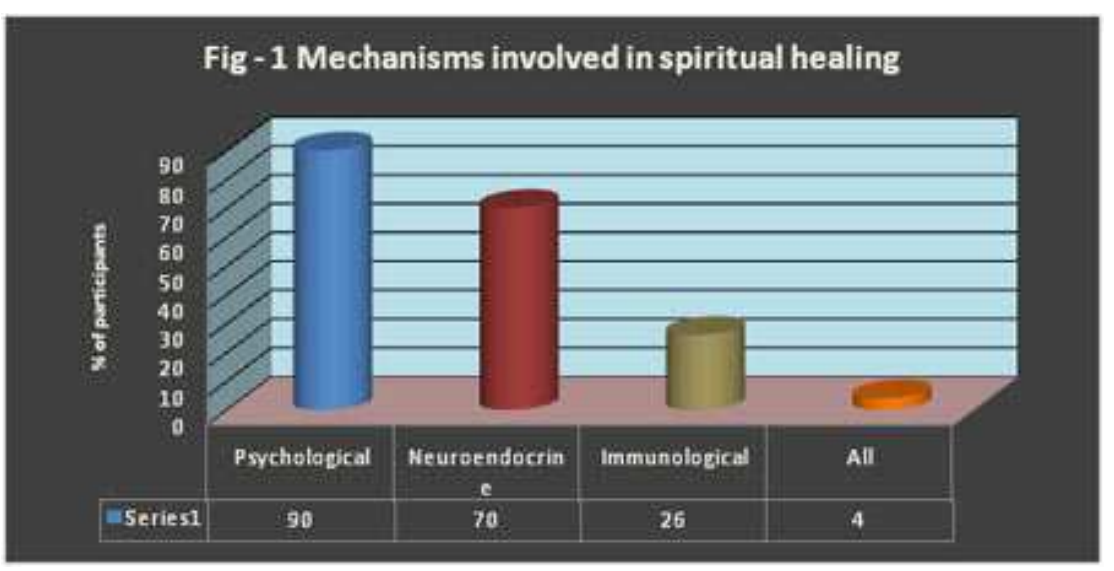



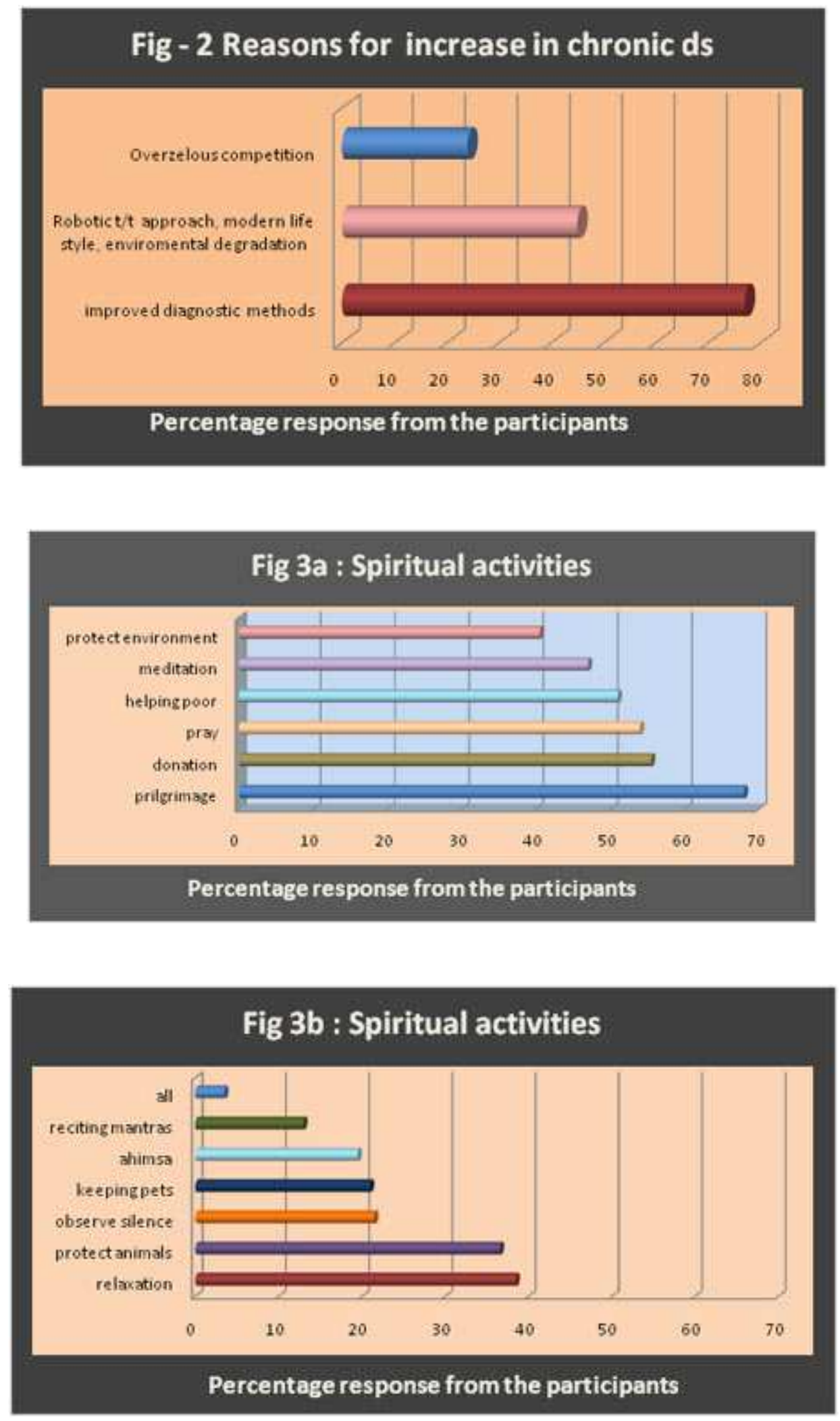
Fig No. 4 - Percentage response from the participants to various spirituality practices

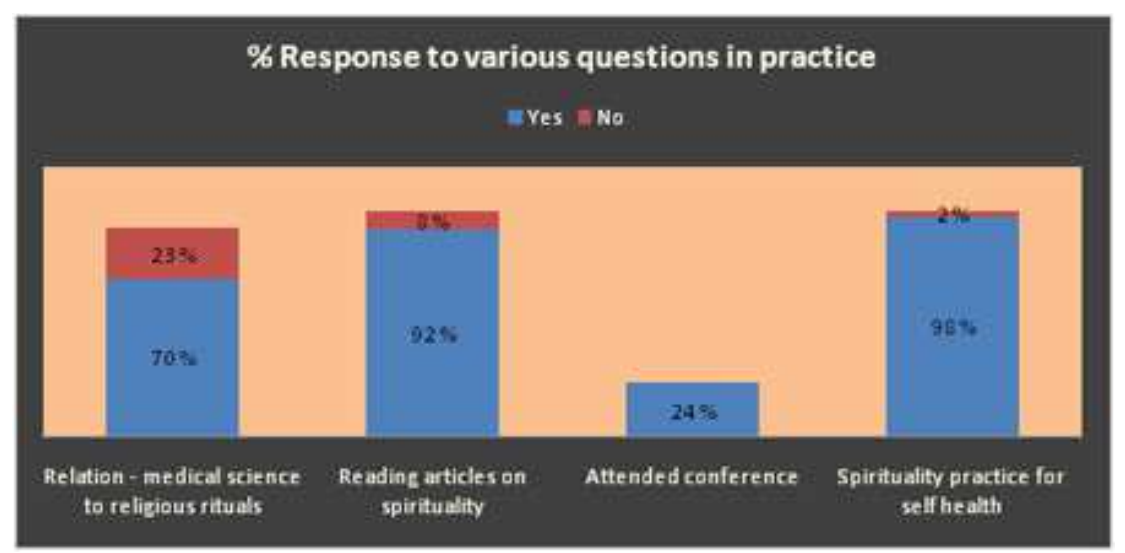

